\title{
Academic Misconduct in Portugal: Results from a Large Scale Survey to University Economics/Business Students
}

\author{
Aurora A. C. Teixeira • Maria de Fátima Oliveira Rocha
}

Published online: 8 June 2010

(C) Springer Science+Business Media B.V. 2010

\begin{abstract}
The phenomenon of cheating in higher education is of overwhelming importance in that the students engaging in these acts are unlikely to have the skills necessary for their future professional life. Despite its relevance, the empirical evaluation of cheating in universities has been almost exclusively focused on the US context. Little is known about cheating at the European level, let alone in Portugal. Even less is explored at the regional level. In this paper we present evidence on the perception of cheating by Portuguese undergraduate students of economics/business degrees. We undertake a large-scale survey, involving 2675 students from all Portuguese mainland public universities (10). We found that copying-favourable environments are associated with a higher propensity to cheat. Moreover, in universities where 'codes of honour' exist, this propensity tends to be lower. Finally, the propensity to copy seems to be highly influenced by the cultural systems and socially-related factors of different regions.
\end{abstract}

Keywords Cheating $\cdot$ University $\cdot$ Students $\cdot$ Portugal $\cdot$ Regions

JEL Codes $\mathrm{A} 22 \cdot \mathrm{I} 23 \cdot \mathrm{R} 19$

\section{Introduction}

Cheating influences the assessment of the stock of human capital through its effect on the quality of the education system, since this is usually achieved on the basis of the "quantity" and "quality" of education (Barro and Lee 2000; Hanushek and Kimbo 2000; Teixeira

\footnotetext{
A. A. C. Teixeira $(\bowtie)$

CEF.UP Faculdade de Economia do Porto, Universidade do Porto, INESC Porto, OBEGEF,

Rua Dr. Roberto Frias, 4200-464 Porto, Portugal

e-mail: ateixeira@fep.up.pt

M. de Fátima Oliveira Rocha

Universidade Fernando Pessoa, Porto, Portugal

e-mail: frocha@ufp.pt
} 
2005). Cheating tends to reduce the efficiency of a country's education system by distorting honest competition among students (Magnus et al. 2002).

The phenomenon of cheating in higher education is of overwhelming importance in that the students engaging in it are unlikely to have the skills necessary for their future professional life and awarding a degree to these individuals may lead to various levels of damage. Indeed, the entry of unfit professionals in the labour market may bring about a number of "social ills", given that in all likelihood they will not be able to perform properly, possibly resulting in several types of damage both to other professionals in the same area and to the institution that trained them. What is more, the entire educational environment can also be affected, as the importance of cheating means that more effort has to be made controlling it, and this effort could be better applied to learning (Dick et al. 2003).

Cheating is a concept that is hard to define. Dick et al. (2003) mention a wide range of possible kinds of cheating, deciding that, on the whole, cheating results in the breach of defined and accepted rules and standards. Copying in examinations is one form of cheating widely referred to in studies dealing with cheating (e.g., Bunn et al. 1992; McCabe and Trevino 1997; Tibbets 1999; Sheard and Dick 2003; Hrabak et al. 2004).

Despite its recognised importance, the empirical evaluation of the cheating phenomenon among university students have been almost exclusively focused on the US context, embracing usually a few universities in a given region. The other non-US related studies involve a restricted set of countries/regions, namely, from outside Europe, Australia, Japan, Israel, and Russia, and, from Europe, The Netherlands and Croatia. In this context, it is fair to say that little is known about the cheating phenomenon at the European level in general and in Portugal in particular. In this paper we aim to provide a contribution to filling this gap by presenting evidence on this illegal behaviour in Portugal, as well as an analysis at regional level, a perspective that has rarely been broached in this regard.

Controlling for the region in which the student resides (on a permanent basis) and added to the determinants of copying normally highlighted in the literature, we propose a new, broader, econometric specification that includes a variable which quantifies the relevance and magnitude of the 'benefits' that students consider they gain by cheating, in terms of a better grade in comparison with not cheating. Moreover, another 'contextual' determinant of the probability of cheating is also suggested, whether or not the educational establishments have a code of honour.

This paper is organised as follows. The next section surveys existing studies on the topic of cheating. In "Methodology for Quantifying the Phenomenon of Academic Dishonesty" the methodology for collecting the data is described, and the following section (University Cheating in Portugal. An Exploratory Analysis of the Data) presents the econometric specification used for evaluating the phenomenon and the results. The last section concludes by discussing the main results of the study.

\section{On the Determinants of Cheating Behaviour: A Review}

With Becker's seminal study (1968) the economics of crime gained renewed importance. Formalising illegal behaviours in terms of a cost-benefit analysis, Becker (1968) defends the economic rationality of people committing criminal acts. He believes that criminal behaviour results from the maximization of the individual utility function in certain risk situations. Crimes are thus only committed if the resulting gains outweigh the expected punishment (Garoupa 2001). There are other complementary forms of theorising illegal behaviour, as described by Ehrlich (1973) and Wolpin (1978), for example. The first study 
can be viewed as a model for taking individual decisions relating to the time allocation variable, consisting of an analysis that follows the same line of reasoning as Becker's model (1968) (decisions weighted for costs and benefits), improving some aspects associated with the model through their exploration not only of the question of costs, but of benefits, too. In addition, Ehrlich's model (1973) makes it possible to forecast the direction of changes between legal versus illegal activities, as well as the magnitude of each of these activities (Horvath and Kolomaznikova 2002). The studies by Becker, Ehrlich and Wolpin are among the more formal approaches, regarded as pioneering, in the analysis of the economics of crime.

More recent studies on cheating (e.g., Bunn et al. 1992; Kerkvliet and Sigmun 1999) are of an essentially empirical nature. They are based on econometric specifications consistent with the assumption of a relation between fraudulent behaviour and the notion of costs and benefits resulting from it. So these studies are adaptations of Becker's crime model to academic misconduct. ${ }^{1}$

Most of studies that examine the importance, in quantitative terms, of cheating in academia (cf. Table 1) show that the dimension of cheating is considerable-over one third of the student population. In one of the pioneering studies by Bunn et al. (1992), concerning an analysis of two higher education courses in Microeconomics in Alabama (US), the authors found that half the students surveyed admitted to having copied. They also found that cheating was 'normal' among students, with $80 \%$ admitting that they had seen a colleague copying and half saying that they had seen a colleague being caught copying. Apart from the magnitude of the phenomenon, unlawful behaviour seems to be rather widely 'internalized' in the student community, with $28 \%$ of students admitting to knowing colleagues who copy regularly. The widespread occurrence of the phenomenon seems to be justified by the fact that most students $(70 \%)$ do not see copying as a serious offence.

In another context (two public universities in the US) and looking at more courses (six Economics classes), Kerkvliet (1994) collected data in two different ways (direct response and random response questionnaires), and found that in the random response questionnaire (which he felt guaranteed greater confidentiality and thus more honest answers), $42 \%$ of students indicated they had copied at least once in an exam.

In a later study, covering 12 classes in the two universities, Kerkvliet and Sigmun (1999) estimated that an average of $12.8 \%$ of the students surveyed had copied at least once. But there was considerable disparity among the groups, ranging from $0.2 \%$ in the least 'deceitful' class and $32 \%$ in the one where cheating was most common. The authors say this disparity is due to the different measures of "intimidation" used in the various classes (higher number of tests per student in more vigilant universities; space per student in the classroom; number of test versions used by the teacher; kind of exam).

Taking a larger population than that of the Bunn et al. (1992) study, Nowell and Laufer (1997) looked at two degrees in the USA (Economics and Accounting) and concluded that the average propensity to commit academic misconduct was around $27 \%$.

More recently, and with reference to other scientific areas, findings by Sheard and Dick (2003) in a study on postgraduate students in Information Technology at a university in Melbourne (Australia) showed that $9 \%$ of students admitted to being involved in serious forms of cheating in exams. In other study on academic misconduct among students from the 2 nd to the 6th year of Medicine, in a Croatian university, Hrabak et al. (2004) found that $94 \%$ admitted to having committed some kind of deceit at least once during their studies. When it came to copying answers or using 'cheat sheets', the percentages were $52.2 \%$ and

\footnotetext{
${ }^{1}$ Rocha and Teixeira (2005) account for the distinct forms of theorising illegal behaviours and adapt Becker's crime model (1968) to cheating.
} 


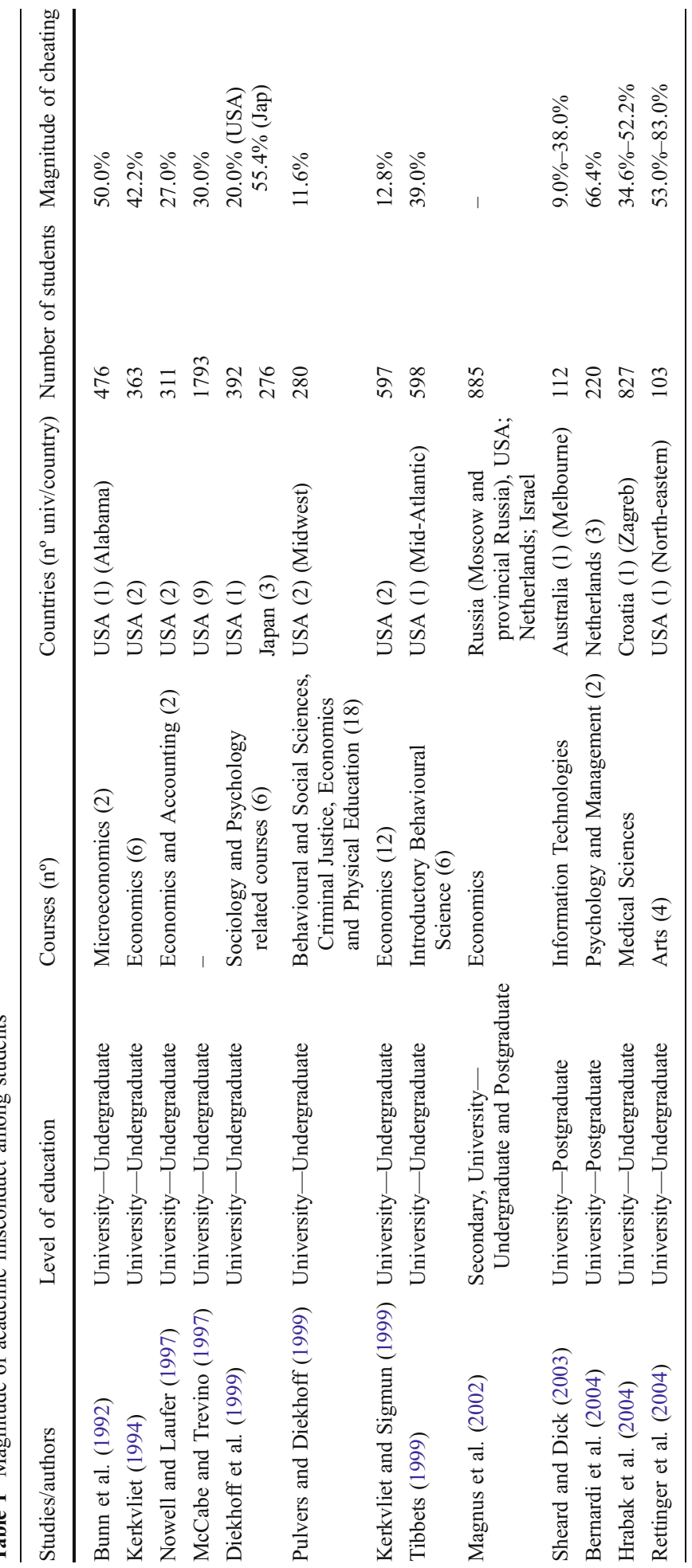


$34.6 \%$, respectively. A considerable percentage (66.4\%) of Psychology and Management students in three Dutch universities admitted to having cheated (Bernardi et al. 2004).

Different studies (including those cited above) systematically indicate a series of determinants for academic dishonesty. These may be grouped into factors associated with student characteristics, factors related to the institution, variables influencing the likelihood of the phenomenon being detected and the respective cost of detection, and also causes associated with the benefits of copying (when they are not caught) and the benefits of not copying. Table 2 provides an overview of the different factors, by group, mentioned in the literature.

The average course mark is a cheating determinant used in most of the studies-Bunn et al. (1992), Kerkvliet (1994), Nowell and Laufer (1997), Kerkvliet and Sigmun (1999) and Hrabak et al. (2004) - although its (statistic) significance is seldom found. Usually a negative relation is expected between this variable and copying in an exam as it is reckoned that students with a high course average would have less to gain from copying than those with a lower average. Although Bunn et al.'s results confirm this assumption, many authors (Kerkvliet 1994; Nowell and Laufer 1997; and Kerkvliet and Sigmun 1999) did not find the course average statistically significant. Notwithstanding, Hrabak et al. (2004) argue that the course average could be relevant in explaining attitudes to cheating. They take the view that students with a higher average have a more negative attitude to copying than those with a lower one, and further disapprove of swapping questions by phone during an exam, and using personal relations to pass an exam.

Concerning grades, we suggest here, linked to the cost/benefit idea, that perhaps more important than the students' average grade/mark, a critical determinant of the propensity to cheat is the students' perceived 'benefits', in terms of a higher grade, which they expect if they copy successfully. In this line, we aim to test the following hypothesis:

Hypothesis 1: The likelihood of copying is increased when the difference between the mark/grade students expect if they copy is positive when compared with the mark/grade that they expect if they do not copy.

Hypothesis 2: The probability of copying is higher the greater the difference between the mark students says they expect if they do in fact copy and the mark if no copying takes place.

Contextual factors and the environment-peer pressure and attitudes towards academic misconduct are also other conditioning factors for the development of dishonest academic practices. In fact, Bunn et al. (1992) found that the likelihood of copying is directly related to observing others doing so, and the perception of the number of students who routinely copy. In other words, the probability of a student having already copied is conditioned by his/her beliefs in relation to other students who copy. Furthermore, these authors assess the perception students have regarding the severity of the punishment applied if they are caught copying and use this and indicators of the climate of cheating perceived by students to evaluate their perception of the percentage who copy. They find evidence for the belief among students that, given the negligible effect of intimidation attached to expected punishments, they are very unlikely to be caught copying. In addition they find that students do not think copying is a serious offence, which could contribute to a greater incidence of this phenomenon.

Hypothesis 3: In copying-favourable environments where permissibility and permeability towards copying is high, students' propensity to copy tends to be higher.

Hypothesis 4: The higher and more serious the perceived sanctions are, fewer incentives students have to perpetrating dishonest behaviours. 
Table 2 Factors influencing the propensity to cheat, by group

\begin{tabular}{|c|c|c|}
\hline Groups of determinants & Determinants & Studies \\
\hline Students characteristics & $\begin{array}{l}\text { - Gender } \\
\text { - Average course grade } \\
\text { - Consumption of alcohol } \\
\text { - Academic year of studies } \\
\text { - Religious preference } \\
\text { - Student Status } \\
\text { - Have failed at least a year } \\
\text { - Moral factors and kind } \\
\text { of personality } \\
\text { - Motivation and competence }\end{array}$ & $\begin{array}{l}\text { Kerkvliet (1994) } \\
\text { Nowell and Laufer (1997) } \\
\text { Whitey (1998) } \\
\text { Kerkvliet and Sigmun (1999) } \\
\text { Tibbets (1999) } \\
\text { Bernardi et al. (2004) } \\
\text { Hrabak et al. (2004) } \\
\text { Rettinger et al. (2004) }\end{array}$ \\
\hline $\begin{array}{l}\text { Factors related with the } \\
\text { education institution }\end{array}$ & $\begin{array}{l}\text { - Dimension and level of class } \\
\text { - Category of teachers } \\
\text { - Existence of an "honour code" } \\
\text { - Classroom environment }\end{array}$ & $\begin{array}{l}\text { Nowell and Laufer (1997) } \\
\text { Whitey (1998) } \\
\text { Pulvers and Diekhoff (1999) } \\
\text { Kerkvliet and Sigmun (1999) } \\
\text { McCabe et al. (2003) }\end{array}$ \\
\hline $\begin{array}{l}\text { Cost of detecting } \\
\text { academic dishonesty }\end{array}$ & $\begin{array}{l}\text { - Teachers' academic category } \\
\text { - Existence of verbal warnings } \\
\text { regarding the resultant consequences } \\
\text { of copying in exams }\end{array}$ & $\begin{array}{l}\text { Bunn et al. (1992) } \\
\text { Kerkvliet and Sigmun (1999) }\end{array}$ \\
\hline $\begin{array}{l}\text { Probability of detecting } \\
\text { copying }\end{array}$ & $\begin{array}{l}\text { - Number of tests by students with the } \\
\text { goal of maintaining good behaviour } \\
\text { - Spatial class occupation by student } \\
\text { - Number of exams versions used } \\
\text { by instructor } \\
\text { - Type of exams }\end{array}$ & Kerkvliet and Sigmun (1999) \\
\hline $\begin{array}{l}\text { Benefits of copying (in the } \\
\text { case of not being caught) }\end{array}$ & $\begin{array}{l}\text { - Expected grade/mark } \\
\text { - Number of "free" hours for the } \\
\text { student during the term } \\
\text { - Type of Courses }\end{array}$ & $\begin{array}{l}\text { Whitey (1998) } \\
\text { Kerkvliet and Sigmun (1999) }\end{array}$ \\
\hline Benefits of not copying & $\begin{array}{l}\text { - Average number of weekly hours } \\
\text { of study }\end{array}$ & $\begin{array}{l}\text { Kerkvliet (1994) } \\
\text { Kerkvliet and Sigmun (1999) }\end{array}$ \\
\hline Others factors & $\begin{array}{l}\text { - Students' opinion of those who } \\
\text { copy or commit other types of } \\
\text { academic dishonesty } \\
\text { - Students perception in light of the } \\
\text { percentage of students who copy and } \\
\text { of rival group behaviours } \\
\text { - Intensity of work ("Workload") } \\
\text { - Pressure not to fail } \\
\text { - Type of courses } \\
\text { - Country/region } \\
\text { - Students' background } \\
\text { - Students' origin }\end{array}$ & $\begin{array}{l}\text { Bunn et al. (1992) } \\
\text { Kerkvliet (1994) } \\
\text { McCabe and Trevino (1997) } \\
\text { Nowell and Laufer (1997) } \\
\text { Whitey (1998) } \\
\text { Diekhoff et al. (1999) } \\
\text { Magnus et al. (2002) } \\
\text { Sheard and Dick (2003) } \\
\text { Hrabak et al. (2004) }\end{array}$ \\
\hline
\end{tabular}


Although McCabe et al. (2003) do not analyse directly the influence of codes of honour on the probability of copying, they examine whether this variable has an effect on the academic integrity of university staff in terms of their attitudes and behaviours. The analysis is based on universities with and without codes of honour. The authors found that universities which have a code of honour have more positive attitudes towards policies of academic integrity and are more willing to allow the system to take measures to warn and discipline students. Furthermore, they confirmed that, in the absence of a code of honour, university faculty members with this experience believe in students being responsible for monitoring their colleagues, recognising the fairness and efficiency of their institutions' policies of academic integrity. Following this line of argument we hypothesise here that:

Hypothesis 5: In universities where 'codes of honour' exist, the propensity to copy among students is lower.

Differences in social factors are likely to comprise an important factor in explaining students' propensity to cheat. For instance, Diekhoff et al. (1999) detect differences and similarities in American and Japanese students copying in exams. Weighting the limitation associated with the distinct composition of the two samples (both in terms of size and associated with various demographic characteristics, such as gender, age and school year), the data show that in comparison with the Americans, the Japanese students are more prone to copy in exams. With regard to social involvement, Diekhoff et al. (1999) consider that if copying is viewed as widespread, it is harder for Japanese students to resist to the pressure of copying or to help their colleagues to do so, given the group and team orientation among Japanese students. In a similar vein, Magnus et al. (2002) conducted an experiment on students in secondary, higher and postgraduate education, in 5 different regions-Moscow, Russia (province), the Netherlands, the USA and Israel-and show that both the level of teaching and the zone lead to students having distinct opinions in relation to academic dishonesty. On average, Russian students are against denouncers, contrary to the views held by the American students on the same behaviour. It was also found, on average, and except for Russia, that secondary school pupils are less tolerant of denouncing when compared with students in higher education, and these are less tolerant than postgraduates.

To the best of our knowledge, no study has so far been conducted focusing on a crossregional analysis of academic dishonesty. Thus little is known about this behaviour among university students coming from different regions of a given country. We hypothesise that:

Hypothesis 6: The propensity to copy is influenced by the regions' cultural systems and socially-related factors.

It is important here to point out that there are other factors indicated in the literature that may influence dishonest behaviour in students, such as gender (Kerkvliet 1994; Nowell and Laufer 1997; Kerkvliet and Sigmun 1999; Tibbets 1999; Hrabak et al. 2004), year of study (Nowell and Laufer 1997; Kerkvliet and Sigmun 1999; Hrabak et al. 2004), and student status (Nowell and Laufer 1997). However the incidence and the strength of these variables are not consensual or clear cut.

\section{Methodology for Quantifying the Phenomenon of Academic Dishonesty}

The main problem linked to the analysis of cheating in academia lies in the fact that it is hard to measure, and researchers have generally used their own information to assess this type of behaviour (Nowell and Laufer 1997). There are four ways to obtain data on 
academic misconduct (Kerkvliet and Sigmun 1999): direct yet discrete observation of the data; the "overlapping error" method; the random answer questions method, and inquiry via the direct questions method. In this study, we have opted for the latter method. Although this method takes no account of problems associated with sensitivity to the kind of questions asked (like the random answers method), meaning that it can induce deviation in the estimates of academic dishonesty (Kerkvliet and Sigmun 1999), it does have simplicity of implementation in its favour, and a wealth of output for analysis. This is why it is often the procedure used (Bunn et al. 1992; Magnus et al. 2002; Sheard and Dick 2003; Hrabak et al. 2004). ${ }^{2}$

We devised a one page questionnaire in line with Bunn et al. (1992) covering a range of questions focusing on the main determinants associated with academic misconduct, adding new variables/questions which in our view are likely to influence the propensity to copy (cf. "On the Determinants of Cheating Behaviour: A Review").

The questionnaire was implemented in all (10) Portuguese public universities, namely to students of Economics and Management. In operational terms, for each school, course, and school year (2nd, 3rd and 4th), the classes with the highest number of enrolled students were selected and the questionnaire was given to students in the classrooms. The survey was conducted between March and December 2005 and resulted in 2675 valid responses.

\section{University Cheating in Portugal. An Exploratory Analysis of the Data}

In comparison to the studies described in "On the Determinants of Cheating Behaviour: A Review", we found that the phenomenon of cheating in the universities analysed reached a relatively high level. In fact, from the students surveyed, $62 \%$ admitted to having copied at least once. Only the study by Hrabak et al. (2004), focusing on Medical students, presents a higher number (94\%). However, this has to do with the fact that the latter study includes under the concept of cheating a set of unlawful practices which go beyond copying (e.g., signing attendance records for a colleague); regarding copying, Hrabak et al. point to figures between $34.6 \%$ and $52.2 \%$ (see Table 1). Other more comparable studies to ours, such as Bunn et al. (1992) present a more similar figure, even though it is lower (50\%).

Generally speaking, in terms of the characteristics of the students surveyed, the data collected points to a slightly higher probability to copy among male students $(62.9 \%$ against $61.4 \%$ of female students) and with intermediary ages. As can be seen in the next graph, students aged 20 to 25 (representing about $75.5 \%$ of the total students surveyed) registered a probability to cheat ranging between $61.2 \%$ and $70.6 \%$, much higher than the $55.1 \%$ recorded among younger students (18-19 years), and 59.4\% among older students (26 years and over) (Graph 1).

Related with the age group is the school year in which the student is enrolled. In this case, the results show a strong relationship between the students' propensity to copy and coming closer to concluding their degree. Students enrolled in the final year (4th year) reveal a $68 \%$ probability to copy whereas their colleagues in the 2 nd year registered $56.5 \%$.

Most of the students surveyed (89.1\%) are 'Regular/Normal Students'. Association Members (AMs) and Working Students (WSs) count for, respectively, 3.1\% and $6.7 \%$ of all the students surveyed. ${ }^{3}$ The latter two groups admitted to a greater propensity to practice

\footnotetext{
${ }^{2}$ Rocha and Teixeira (2005) provide a detailed description of the different methods, presenting their relative strengths and weaknesses.

${ }^{3}$ There is another category, 'Others', which includes broadly speaking students from the Portuguesespeaking Countries, Erasmus students, Armed Forces, etc., who represent $1.1 \%$ of the students surveyed.
} 


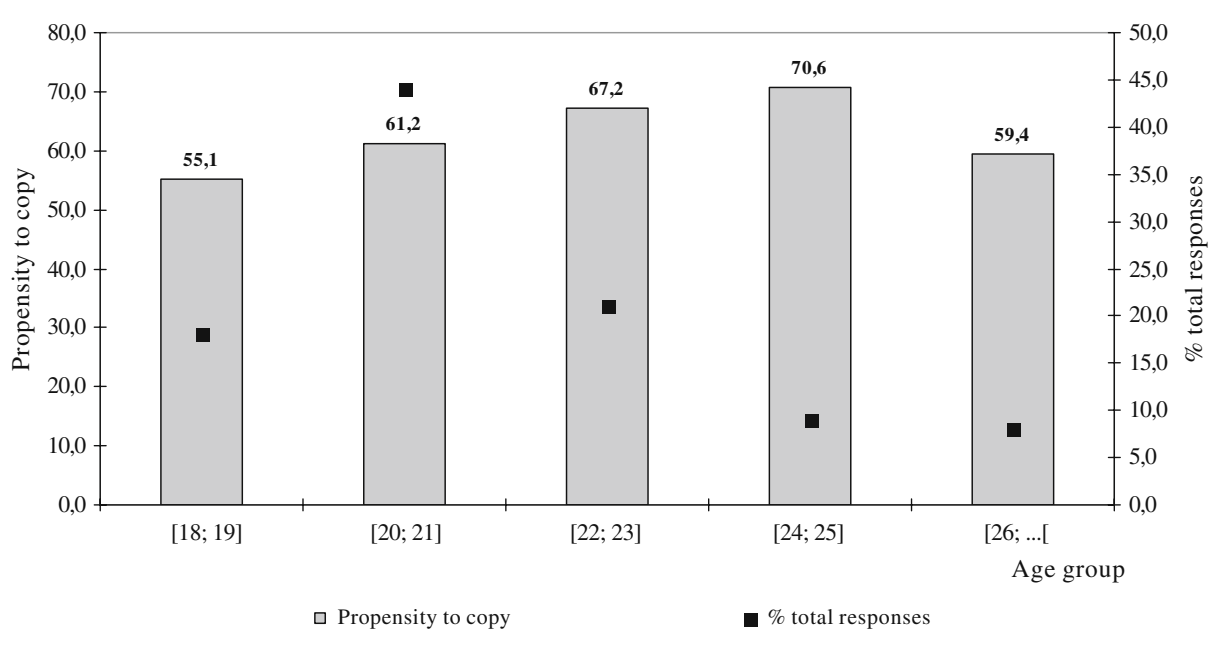

Graph 1 Propensity to copying by age group

dishonest acts academically, namely $66.3 \%$ (AMs) and $65.1 \%$ (WSs), against the $62.1 \%$ of the so-called 'regular' students, which may possibly reveal that AMs and WSs have less time to dedicate to study.

The data in this exploratory analysis seem to confirm existing studies on the inverse relationship between student's performance (proxied by the average academic grade) and the respective propensity to cheat. In fact, as can be seen in Graph 2, the students with better academic performance (average grade of 16 or higher on a scale from 0-20) admit on average to a propensity to copy of $37 \%$, a figure which is far below the one of their less accomplished colleagues (average grades between 10 and 12), who reveal a propensity to cheat of $64.8 \%$.

It is interesting to analyse the degree of heterogeneity of the phenomenon of cheating in regional terms, namely when applying the territorial nomenclatures NUTs II and III. In this survey, the students were asked to identify the respective municipality of permanent residence. Although $8 \%$ of the students did not answer this question, the valid answers (2416) allowed for a sound analysis of the relationship between the student's 'geographic origin', i.e., the socio-cultural context of origin and the respective behaviour in what concerns cheating.

As can be seen in Table 3, the criterion for regional division by NUTs II reveals that most of the students surveyed (42.8\%) come from the Northern region, followed by the students from the Centre (22.3\%) and those from Lisbon and the Tagus Valley $(22.3 \%)$, which follows closely the regional distribution of enrolled students. ${ }^{4}$

Based on the figures presented in Table 3, we can conclude that it is the students from the Alentejo region who revealed the highest propensity to copy $(80.1 \%)$, although a higher percentage (12.5\%) of students from the Autonomous Regions of the Azores admitted to committing this act 'often or always'. It was also this region, together with the Algarve, which had the highest percentage of students stating that they had never copied.

\footnotetext{
${ }^{4}$ The average 'response rate' (total students surveyed over total students enrolled) was 37.5\%, ranging from a minimum of $17.3 \%$ to a maximum of $52.0 \%$. It is important to stress that this 'response rate' is underestimated as we consider students enrolled in classes that had the highest number of enrolments in a given year; thus, it is highly likely that these classes have students from several schooling years due to retentions.
} 


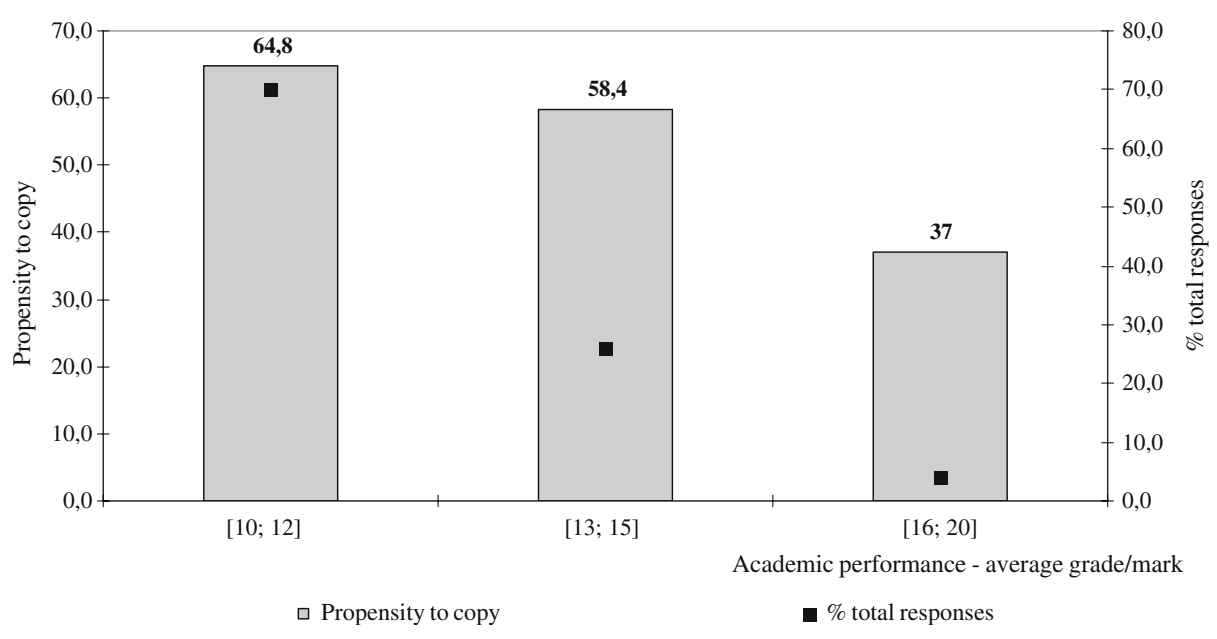

Graph 2 Propensity to copying according to academic performance

As can be seen on the map, the NUTs III regions of Pinhal Interior Norte, Beira Interior Sul, Lezíria do Tejo, Alentejo Litoral, Alto Alentajo and Alentejo Central have the highest percentage (over $78.9 \%$ ) of students who admitted to having copied 'at some time'. At the extreme opposite (propensity to copy less than 57.1\%), are the NUTs III, Alto Trás-osMontes, Baixo Mondego, Pinhal Litoral, Serra da Estrela, Península de Setúbal and Algarve. ${ }^{5}$ With a higher frequency of answers (20\% and $15 \%$ of the total surveyed), Grande Porto and Grande Lisboa are located in the 'average-lower' group of propensity to copy, presenting similar percentages, even though they are lower in Grande Porto $(57.1 \%$ against $58.9 \%$ for Grande Lisboa).

Thus, despite the fact that the magnitude of the phenomenon of cheating is significant in all the NUTs III regions (all presenting figures over 50\%), there seems to be a certain amount of heterogeneity of behaviours in what concerns the intensity of this misconduct, denoting at the outset the relevance of socio-cultural factors associated to the student's geographic origin (Graph 3).

An analysis of the cheating phenomenon can also be conducted from the perspective of the perception students have in relation to the associated context, which can be analysed by the frequency with which the practice of copying occurs, by the awareness of other students who copy regularly and the by opinion held on the importance of the act of copying in the respective University.

Notwithstanding that $62 \%$ of the students surveyed admitted to having copied at some time, direct observation on the part of these students of other colleagues cheating is admitted by almost all the students surveyed (92.5\%). This reflects great familiarity with the phenomenon on the part of students in Economics and Management in Portuguese public higher education.

An analysis of Table 4 allows us to characterise the phenomenon of "observing cheating" by NUTs II. Although greater in magnitude, the percentage of students who have at some time seen others copying corresponds to the student's propensity to copy in terms of scale. In fact, it is in the Algarve and the Autonomous Region of the Azores that a lower

\footnotetext{
${ }^{5}$ The Autonomous Region of the Azores (not represented in the graph) is included in the group of NUTs with students with a lower propensity to copy $(50 \%)$.
} 
Table 3 NUTs II regional distribution of the propensity to copy (in\%)

\begin{tabular}{lccccc}
\hline & \multicolumn{2}{c}{$\%$ \% total students in each region } & Propensity to copy $\begin{array}{c}\text { \% total students } \\
\text { surveyed }(n=2416)\end{array}$ \\
\cline { 2 - 4 } & Never & Sometimes & Often or always & & \\
\hline North & 38.3 & 59.1 & 2.6 & 61.7 & 42.8 \\
Centre & 40.0 & 58.3 & 1.7 & 60.0 & 22.3 \\
Lisbon and Tagus Valley & 39.2 & 58.7 & 2.1 & 60.8 & 22.3 \\
Alentejo & 19.9 & 74.4 & 5.7 & 80.1 & 7.4 \\
Algarve & 45.4 & 53.7 & 0.9 & 54.6 & 4.5 \\
Azores & 50.0 & 37.5 & 12.5 & 50.0 & 0.3 \\
Madeira & 41.7 & 58.3 & 0.0 & 58.3 & 0.5 \\
\hline
\end{tabular}

Calculations made by the authors based on direct questionnaires to students, in the periods FebruaryDecember 2005

Graph 3 Mapping propensity to copy in Continental Portugal by regions (NUTs III)

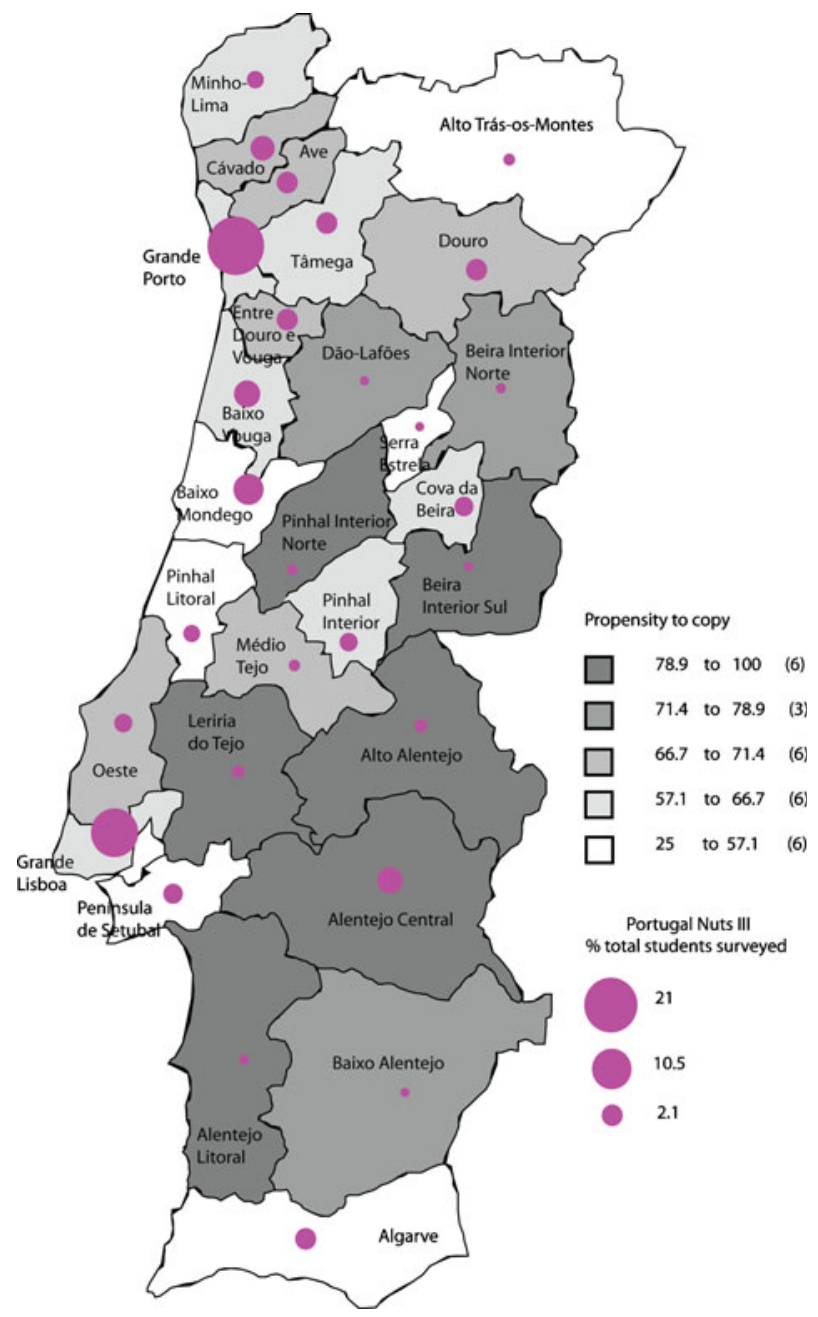


Table 4 Probability of "seeing other students copying" (in\%) by NUTs II

\begin{tabular}{lrcccc}
\hline & \multicolumn{2}{c}{$\%$ total surveyed in each region } & $\begin{array}{c}\text { Probability of "seeing } \\
\text { other students copying" }\end{array}$ & $\begin{array}{l}\text { \% of students in } \\
\text { each region }\end{array}$ \\
\cline { 2 - 5 } & Never & Sometimes & Often or always & \\
\hline North & 8.3 & 68.3 & 23.4 & 91.7 & 42.8 \\
Centre & 6.7 & 69.4 & 23.9 & 93.3 & 22.3 \\
Lisbon and Tagus Valle & 7.1 & 71.6 & 21.3 & 92.9 & 22.3 \\
Alentejo & 2.8 & 63.5 & 33.7 & 97.2 & 7.4 \\
Algarve & 12.0 & 61.1 & 26.9 & 88.0 & 4.5 \\
Azores & 25.0 & 62.5 & 12.5 & 75.0 & 0.3 \\
Madeira & 0.0 & 58.3 & 41.7 & 100.0 & 0.5 \\
\hline
\end{tabular}

Calculations made by the authors based on direct questionnaires to students in the periods FebruaryDecember 2005

percentage of students ( $88 \%$ and $75 \%$, respectively) admitted to having seen other colleagues commit academic misconduct. On the other hand, the Alentejo appears here again as the region where cheating seems more widespread. Note that slightly over $90 \%$ of the students surveyed with permanent residence in the Northern Region have seen other students copying, of which $68.3 \%$ said such acts were 'sporadic' and $23.4 \%$ stated that it was seen 'often or always'.

It is interesting to note that on the aggregate the percentage $(23.9 \%)$ of students who state they have regularly seen someone (known or not) copying is far lower than the percentage of those who admitted to knowing someone who copies regularly (59.4\%). This means a relative familiarity with the phenomenon of copying and its generalised occurrence among the group of 'friends' of the student surveyed, and therefore a relative permissiveness in relation to the issue. In fact, although 'copying' is considered by about half the students as a serious problem $(11.3 \%)$ or at least an issue that deserves some attention $(37.3 \%)$, most of the student population $(51.4 \%)$ considers that the practice of copying is not really a problem or is merely a minor problem without much relevance.

In terms of elements associated to the perception of the sanctions associated with cheating, about half the students stated that they have already seen other students being caught cheating. However, the individual acknowledgement that this practice has been detected is far lower, only $5 \%$ admitted to having been caught at any time. Given the magnitude of the phenomenon of copying and especially the fact that it is generally observed by many of the students, from the data collected, it seems that being caught cheating does not carry serious sanctions, outside the test/exam setting where the cheating took place. As a matter of fact, a large majority of university students $(83.3 \%)$ expect that, if caught copying, the highest sanction applied is that of having the test annulled (62\%) and possibly not being allowed to take other exams in the subject during that academic year $(21.3 \%)$, which in practical terms, corresponds to failing the subject.

An important aspect which highlights the need for means to prevent copying (e.g., supervisors) derives from the fact that $52.6 \%$ of the students surveyed admitted that in the absence of supervisors or other types of sanctions, they would dedicate less time to study. Even more disquieting is the fact that about $30 \%$ of the students stated that they would dedicate $40 \%$ or over less time to study than usual if supervisors were absent from exams. When taking into account the percentage of students who have admitted to having copied at some time $(62 \%)$, we can conclude that exam supervisors are seen as an effective 'impediment' to the practice of this dishonest act. 
From the calculation of Pearson's linear correlation coefficient, we find that the probability of copying appears statistically and positively correlated with the variation in the benefits gained from successful copying, the frequency of seeing other students copying and being caught copying, with the familiarity of those who copy regularly, with the influence of supervisors on time spent studying, and with the school year in which students are enrolled. Thus, the perception of a higher grade resulting from copying encourages students to practice this act. Cheating is thus all the more probable the greater the expected difference in grades. On the other hand, seeing other students copy regularly seems to be associated with a higher probability for this practice to occur (which may reflect inefficiency in the sanctions applied). Furthermore, the lower the percentage of time spent studying due to the knowledge that there will be no exam supervisors, the higher the probability of copying. Finally, students who are closer to concluding their degrees are more inclined to copying.

The probability of copying is also statistically, but in this case negatively, correlated with the student's average grade (academic performance), the perception of the gravity of the act of copying and the severity of the sanctions. The negative balance obtained for the set of variables that characterise this issue and the punishments associated with the phenomenon of cheating reveal that students who do not know other students who copy regularly tend to admit that they copy less and that the awareness of the gravity of the act reduces the probability of copying (Table 5).

\section{Assessing the Determinants of Academic Cheating: Model Specification and Presentation of Results}

The aim here is to assess which are the main determinants of the propensity to cheat by university students. The nature of the data observed regarding the dependent variable [Have you ever copied in an exam? (1) Yes; (0) No] dictates the choice of the estimation model. Conventional estimation techniques (e.g., multiple regression analysis), in the context of a discrete dependent variable, are not a valid option. Firstly, the assumptions needed for hypothesis testing in conventional regression analysis are necessarily violated - it is unreasonable to assume, for instance, that the distribution of errors is normal. Secondly, in multiple regression analysis predicted values cannot be interpreted as probabilities - they are not constrained to fall in the interval between 0 and 1.6 The approach used, therefore, will be to analyse each situation in the general framework of probabilistic models.

$$
\operatorname{Prob}(\text { event } j \text { occurs })=\operatorname{Prob}(Y=j)=F[\text { relevant effects: parameters }] \text {. }
$$

In the model of likelihood to cheat, it is believed (cf. "On the determinants of cheating behaviour: a review") that a set of factors, such as students' expected benefits/costs of copying, contextual factors, country of origin, among other variables, gathered in a vector $X$, explain the outcome, so that

$$
\operatorname{Prob}(Y=1)=F(X, \beta) \text { and } \operatorname{Pr} o b(Y=0)=1-F(X, \beta) .
$$

The set of parameters $\beta$ reflects the impact of changes in $X$ on the likelihood of 'copying'. The problem at this point is to devise a suitable model for the right-hand side of the equation. The requirement is for a model that will produce predictions that are

\footnotetext{
${ }^{6}$ The logistic regression model is also preferred to another conventional estimation technique, discriminant analysis. According to Hosmer and Lemeshow (1989), even when assumptions required for discriminant analysis are satisfied, logistic regression still performs well.
} 


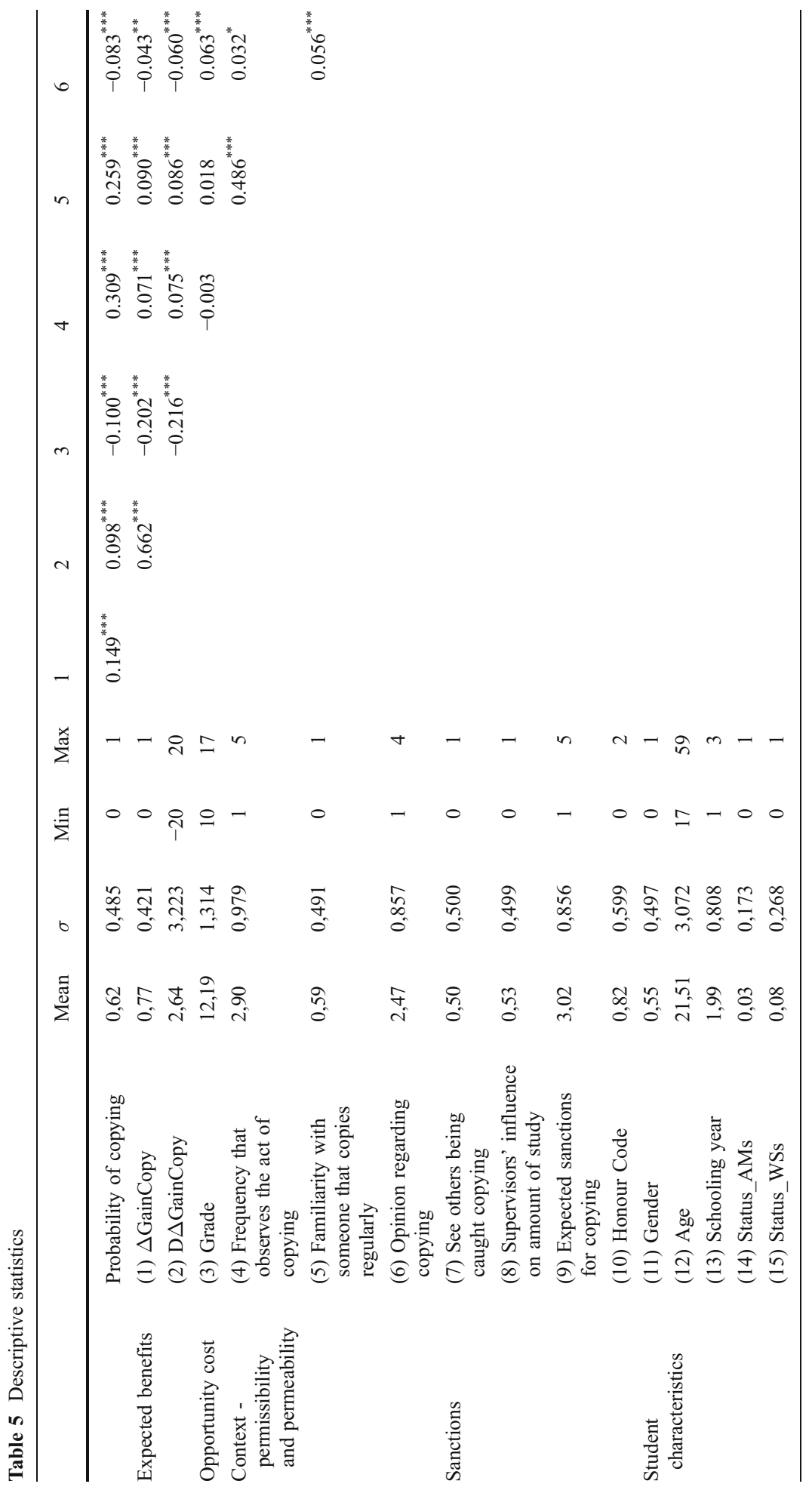




\begin{tabular}{|c|c|c|c|c|c|c|c|}
\hline$\cong$ & 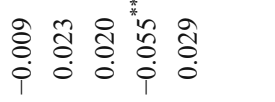 & ते & $\stackrel{\infty}{\circ}$ & ๙ి. & तิ & $\stackrel{\tilde{\sigma}}{\circ}$ & 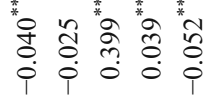 \\
\hline \pm & 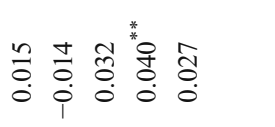 & 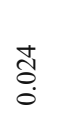 & ¿্రి & $\stackrel{n}{a}$ & $\begin{array}{l}\underbrace{0}_{0} \\
0 \\
0 \\
0 \\
0\end{array}$ & ते & 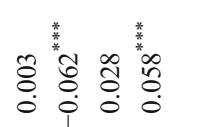 \\
\hline$\cong$ & 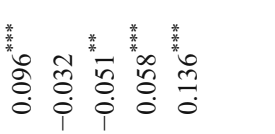 & $\stackrel{*}{\infty}$ & $\stackrel{\infty}{\circ}$ & $\stackrel{*}{\stackrel{*}{*}}$ & $\stackrel{\infty}{0}$ & $\stackrel{\overline{0}}{0}$ & 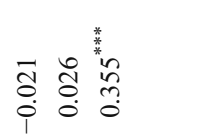 \\
\hline$\simeq$ & 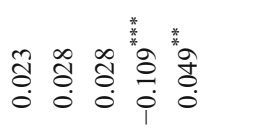 & : & $\stackrel{\circ}{\circ}$ & 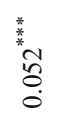 & 俈早 & ठे & 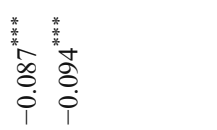 \\
\hline$=$ & 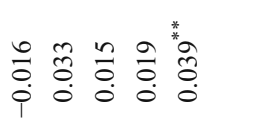 & \begin{tabular}{l}
3 \\
\multirow{3}{*}{$: 0$} \\
0 \\
0 \\
0
\end{tabular} & $\stackrel{8}{8}$ & 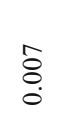 & $\begin{array}{l}n \\
0 \\
0 \\
0\end{array}$ & 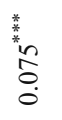 & \&̊ \\
\hline 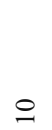 & 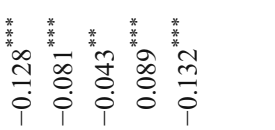 & $\stackrel{*}{*}$ & ầ & 草 & $\begin{array}{l}\tilde{o} \\
\dot{\varphi}\end{array}$ & $\stackrel{\substack{+\infty}}{-\infty}$ & \\
\hline$a$ & 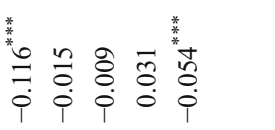 & 范 & $\stackrel{*}{*}$ & $\begin{array}{l}* \\
\text { *o } \\
0 \\
0 \\
0\end{array}$ & $\begin{array}{l}8 \\
\dot{0} \\
0\end{array}$ & & \\
\hline$\infty$ & 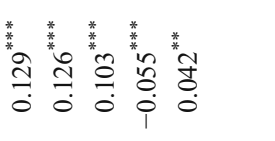 & $\stackrel{*}{*}$ & $\hat{o}$ & : & & & \\
\hline$r$ & 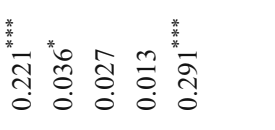 & : & 菳 & & & & \\
\hline & 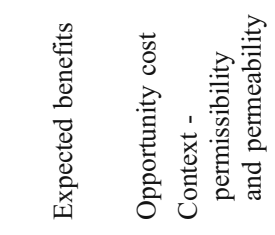 & & & 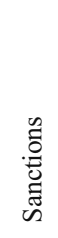 & & & 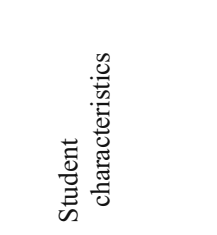 \\
\hline
\end{tabular}


consistent with the underlying theory. For a given vector of regressors, one would expect $\lim _{\beta^{\prime} X \rightarrow+\infty} \operatorname{Prob}(Y=1)=1$ and $\lim _{\beta^{\prime} X \rightarrow-\infty} \operatorname{Prob}(Y=1)=0$.

Partly because of its mathematical convenience, the logistic distribution, $\operatorname{Pr} o b(Y=1)=$ $\frac{1}{1+e^{-\beta^{\prime} X}}$, has been used in many applications (Greene 2003). Rearranged in terms of the log odds, ${ }^{7}$ this expression is the so-called logit model.

The probability model is a regression of the following kind: $E(Y \backslash X)=0\left[1-F\left(\beta^{\prime} X\right)\right]+$ $1\left[F\left(\beta^{\prime} X\right)\right]=F\left(\beta^{\prime} X\right)$. Regardless of the distribution used, it is important to note that parameters of the model, like those of any non-linear regression model, are not necessarily the marginal effects. In general, $\frac{\partial E(Y \backslash X)}{\partial X}=\frac{d F\left(\beta^{\prime} X\right)}{d\left(\beta^{\prime} X\right)} \beta=f\left(\beta^{\prime} X\right) \beta$, where $f($.$) is the density$ function that corresponds to the cumulative distribution, $F($.$) .$

For the logistic distribution, $\frac{d \Lambda\left(\beta^{\prime} X\right)}{d\left(\beta^{\prime} X\right)}=\frac{e^{\beta^{\prime} X}}{\left(1+e^{\beta^{\prime} X}\right)^{2}}=\Lambda\left(\beta^{\prime} X\right)\left[1-\Lambda\left(\beta^{\prime} X\right)\right]$. Thus, in the logit model, $\frac{\partial E[Y \backslash X]}{\partial X}=\Lambda\left(\beta^{\prime} X\right)\left[1-\Lambda\left(\beta^{\prime} X\right)\right] \beta$. It is obvious that these values will vary with the values of $X$. In interpreting the estimated model, it will be useful to calculate this value at, say, the means of the regressors and, where necessary, other pertinent values. In the logistic regression, the parameters of the model are estimated using the maximum-likelihood method (ML). That is, the coefficients that make observed results most "likely", given the assumptions made about the error distribution, are selected.

The empirical assessment of the propensity to copy is based on the estimation of the following general logistic regression:

$$
\begin{aligned}
P(\text { copy })= & \frac{1}{1+e^{-Z}} ; \text { with } Z=\beta_{0}+\beta_{1} \Delta \text { GainCopy }+\beta_{2} D \Delta \text { GainCopy }+\beta_{3} \text { Grade } \\
& +\beta_{4} \text { Contextual }+\beta_{5} \text { Sanctions }++\beta_{6} \text { HCode }+\beta_{7} \text { Regions }+\beta_{\mathbf{8}} \text { StudentCharact }+\varepsilon_{i}
\end{aligned}
$$

In order to have a more straightforward interpretation of the logistic coefficients, it is convenient to consider a rearrangement of the equation for the logistic model, in which the logistic model is rewritten in terms of the odds of an event occurring.

Writing the logistic model in terms of the odds, the logit model is obtained

$$
\begin{aligned}
\log \left(\frac{\operatorname{Prob}(\text { copy })}{\text { Prob }(\text { not copy })}\right)= & \beta_{0}+\beta_{1} \Delta \text { GainCopy }+\beta_{2} D \Delta \text { GainCopy }+\beta_{3} \text { Grade }+\beta_{\mathbf{4}} \text { Contextual } \\
& +\beta_{\mathbf{5}} \text { Sanctions }++\beta_{6} \text { HCode }+\beta_{7} \text { Regions }+\beta_{\mathbf{8}} \text { StudentCharact }+\varepsilon_{i}
\end{aligned}
$$

The logistic coefficient can be interpreted as the change in the log odds associated with a one-unit change in the independent variable. Then $e$ raised to the power $\beta_{i}$ is the factor by which the odds change when the $i^{\text {th }}$ independent variable increases by one unit. If $\beta_{i}$ is positive, this factor will be greater than 1 , which means that the odds are increased; if $\beta_{i}$ is negative, the factor will be less than one, which means that the odds are decreased. When $\beta_{i}$ is 0 , the factor equals 1 , which leaves the odds unchanged. **

In the case data corroborates our Hypothesis 1, "The likelihood of copying is increased when the difference between the mark/grade students expect if they copy is positive when compared with the mark/grade that they expect if they do not copy", the estimate of $\beta_{1}$ should emerge as positive and significant for the conventional levels of statistical significance (that is, $1 \%, 5 \%$ or $10 \%$ ).

The estimates of the $\beta s$ are given in Table 6 below, related with two alternative models, one (Model I) that does not control for the regional (NUTs III) dummy variables concerning students' origin and Model II that does.

\footnotetext{
${ }^{7}$ The odds of an event occurring are defined as the ratio of the probability that it will occur to the probability that it will not.
} 
Table 6 Determinants of academic misconduct among university students (ML estimation)

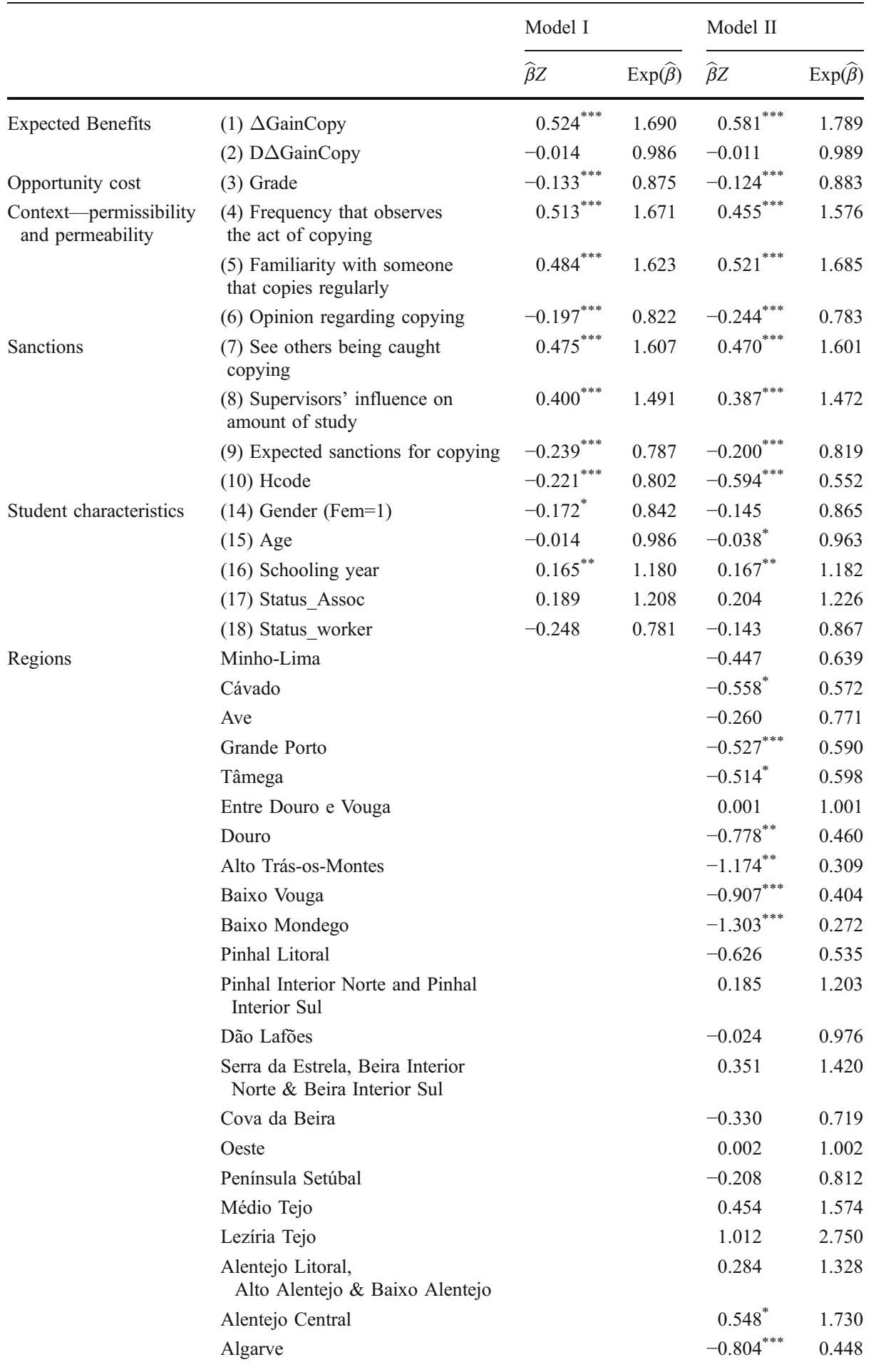


Table 6 (continued)

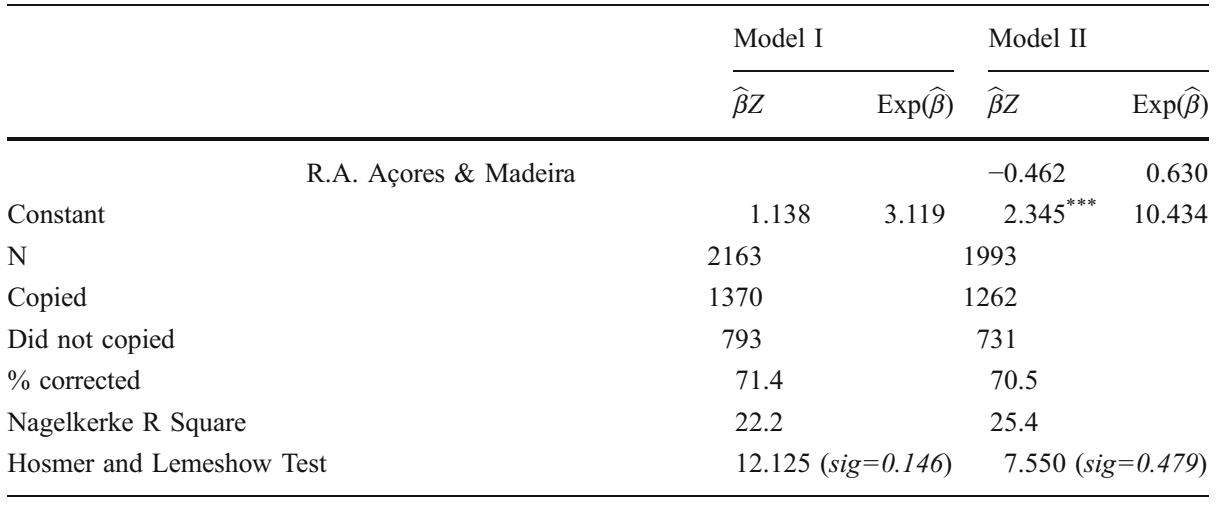

Significant at ${ }^{* * *} 1 \% ;{ }^{* *} 5 \%$ and ${ }^{*} 10 \%$

\section{Conclusions}

According to Hosmer and Lemeshow's test both models reveal a good fit. ${ }^{8}$ It is also clear that the fact that estimates are robust in the sense that controlling or not for the regional origin of students does not change significantly the magnitude, the significance or the signs of those estimates. Excluding gender and age coefficients for all the remaining variables in both models, the sign and significance of the coefficients are similar.

The expected gain in terms of a higher grade when copying is successful is statistically significant and the correspondent coefficient has the expected (positive) sign, corroborating therefore Hypothesis 1 . According to our results, the odds ratio ${ }^{9}$ changes by about 1.8 when the difference between the mark students expect if they copy is positive when compared with the mark they expect if they do not copying. However, nothing can be concluded concerning the absolute value of the difference between expected marks (between copying and not copying) and the odds of copying. In this line, Hypothesis 2- "The probability of copying is higher the greater the difference between the mark students say they expect if they copy and the mark if no copying takes place"-cannot be corroborated by our data. The student's academic performance, assessed by his/her grade, negatively influences the propensity to commit fraud - the higher the student's grade (i.e., the higher the opportunity cost) the lower, on average, the probability of copying.

Copying-favourable environments-proxied by the frequency with which students observe the act of copying, the familiarity with someone that copies regularly and students' opinion regarding copying - are associated with a higher propensity to commit this illegal behaviour. The negative and significant sign of the coefficient associated to the last variable indicates that the more serious copying is, the lower the propensity of students to commit academic misconduct. In summary, Hypothesis 3- "In copying-favourable environments where permissibility and permeability towards copying is high, students' propensity to copy tends to be higher" - is confirmed.

\footnotetext{
${ }^{8}$ This test null hypothesis denotes that the values predicted by the model are not significantly different from the observed values. Given that the $p$-value is not significant for standard values, this hypothesis is not rejected, leading us to the conclusion that both models foresee reality reasonably well.

${ }^{9}$ Ratio of the probability of copying to the probability of not copying.
} 
Our results also show that those students who admit to studying less when there are no supervisors have a higher propensity to copy in exams. Additionally, the negative sign related to estimate of the severity of the sanctions confirms Hypothesis 4, since the higher and more serious the punishments as perceived by students, fewer are the incentives they have to perpetrate dishonest behaviours. Even though having seen other students being caught copying has a positive influence on the probability of copying, this outcome combined with the previous results, leads to the conclusion that existing sanctions have no efficient effects. Furthermore, the existence of 'codes of honour' or any written form which sets forth the conduct and sanction applied in a situation where copying is detected reflects a lower propensity to copy, confirming therefore Hypothesis 5- "In universities where 'codes of honour' exist, the propensity to copy among students is lower".

The school year in which students are enrolled arises here as the most (statistically) important student characteristic determining cheating behaviour. Results reveal that the closer a student is to concluding his/her degree, the higher the odds of copying. Gender is (statistically) relevant when we do not control for the regional origin of the students (Model I) - here the negative sign of the coefficient estimate means that, ceteris paribus, female students are less prone to commit fraudulent acts. Age emerges as a negative relevant determinant when we control for regional factors reflecting the fact that, on average, all other factors remaining constant, senior students are less likely to perpetrate illegal acts than their younger counterparts.

Interestingly, when we control for a set of determinants of cheating behaviour, student status fails to be a statistically relevant variable - all else being constant, having AM or WS status when compared to the 'regular' student status does not seems to result in a different attitude towards cheating.

There is a significant heterogeneity in propensity to copy in terms of regions. In fact, as we detailed in "University Cheating in Portugal. An Exploratory Analysis of the Data", students who reside on a permanent basis in southern, inland regions, especially in areas of Alentejo, present a significantly higher propensity to commit academic misconduct than students from other areas of Portugal. This descriptive analysis does not however control for other fraud determinants, namely gender, age, grade, and so forth. The estimated Model II shows that controlling for a reasonable number of factors that are likely to influence students' perception of cheating, students coming from regions such as Baixo Mondego and Alto Trás-os-Montes reveal substantially lower (around 70\%) odds of copying than those coming from Grande Lisboa (the default region). The odds of copying are forty per cent lower in students resident in the northern regions of Grande Porto, Cávado and Tâmega when compared with their Lisbon counterparts. In contrast, students resident in the Alentejo Central region observe statistically significant higher odds $\left(1.73\left(=e^{\widehat{\beta}}\right)\right)$ of copying than their homologous counterparts from the Lisbon area. From this we can conclude that "The propensity to copy is influenced by the regions' cultural systems and socially-related factors", that is, the data seems to corroborate Hypothesis 6.

Although beyond of the restricted scope of this paper, it would be quite interesting and challenging to study in greater detail the origin of such a diversity of regional patterns in what concerns academic cheating behaviours.

Acknowledgments We are deeply indebt to all students that responded the survey and to the following individuals (in alphabetic order) for permitting and/or implementing the questionnaire underlying this study.

Directors: Antonieta Cunha Sá (UNL/University Nova of Lisboa), Artur Cristóvão (UTAD/University of Alto Douro e Tràs-os-Montes), Fernando Almeida (Economics and Management School/University of Minho), Joaquim Borges Gouveia (Economics, Business and Industrial Engineering Department/University of Aveiro), José Pereirinha (ISEG/University of Lisbon), José Silva Costa (FEP/University of Porto), Manuel 
Branco (Faculty of Economics/University of Évora), Paulo Rodrigues (Faculty of Economics/University of Algarve), Pedro Botelho (FEUC/University of Coimbra).

Department Coordinators: Carlos Arriaga (Economics Department/University of Minho), Fernanda Nogueira (Bussiness Department/University of UTAD), José Caldas (Economics Department/University of UTAD).

Professors/Researchers: Ana Maria Rodrigues (University of Coimbra), António Caleiro (University of Évora), Arménio Rego (University of Aveiro), Aurora Galego (University of Évora), Carla Amado (University of Algarve), Carlos Ferreira (University of Aveiro), Carlota Quintal (University of Coimbra), Efigénio Rebelo (University of Algarve), Elisabete Félix (University of Évora), Fernando Cardoso (University of Algarve), Francisco Torres (University of Aveiro), Henrique Albergaria (University of Coimbra), Joana Costa (University of Beira Interior), João Paulo Costa (University of Coimbra), José Belbute (University of Évora), José Novais (University of Évora), Margarida Saraiva (University of Évora), Maria Graça Baptista (University of Açores), Maria João Alves (University of Coimbra), Maria João Carneiro (University of Aveiro), Maria João Thompson (University of Minho), Miguel Lebre de Freitas (University of Aveiro), Óscar Afonso (FEP/University of Porto), Patrícia Valle (University of Algarve).

Other university staff: Ana Paula Teixeira and Cristina Santana (University of Algarve), Sónia Fidalgo (University of Aveiro) and Leonor Dias (University of Coimbra)

A final word of appreciation to Luzia Belchior (FEP-Administrative Office) for her valuable assistance with the optical reading of the survey questionnaires.

\section{References}

Barro, R. J., \& Lee, J. W. (2000). International data on educational attainment updates and implications. NBER Working Paper $\mathrm{n}^{\mathrm{o}}$ 7911, National Bureau of Economic Research.

Becker, G. S. (1968). Crime and punishment: an economic approach. Journal of Political Economy, 76, 168-217.

Bernardi, R. A., Metzger, R. L., Bruno, R. G. S., Hoogkamp, M. A. W., Reyes, L. E., \& Barnaby, G. H. (2004). Examining the decision process of students' cheating behaviour: an empirical Study. Journal of Business Ethics, 50, 397-414.

Bunn, D. N., Caudill, S. B., \& Gropper, D. M. (1992). Crime in the classroom: an economic analysis of undergraduate student cheating behavior. Journal of Economic Education, 23, 197-207.

Dick, M., Sheard, J., Bareiss, C., Carter, J., Joyce, D., Harding, T., et al. (2003). Addressing student cheating: definitions and solutions. ACD SIGCSE Bulletin, 35(2), 172-184.

Diekhoff, G. M., LaBeff, E. E., Shinohara, K., \& Yasukawa, H. (1999). College cheating in Japan and the United States. Research in Higher Education, 40(3), 343-353.

Ehrlich, I. (1973). Participation in illegitimate activities: a Theoretical and empirical investigation. Journal of Political Economy, 81, 521-65.

Garoupa, N. (2001). Optimal law enforcement when victims are rational players. Economics of Governance, $2,231-242$.

Greene, W. H. (2003). Econometric analysis. Prentice Hall.

Hanushek, E., \& Kimbo, D. (2000). Schooling, labor-force quality and growth of nations. The American Economic Review, 90(5), 1184-208.

Horvath, R., \& Kolomaznikova, E. (2002). Individual decision-making to commit a crime: early models. Law and Economics, 0210001, 1-17.

Hosmer, D., \& Lemeshow, S. (1989). Applied logistic regression. New York: Wiley.

Hrabak, M., Vujaklija, A., Vodopivec, I., Hren, D., Marusic, M., \& Marusic, A. (2004). Academic misconduct among medical students in a postcommunist country. Medical Education, 38(3), 276-285.

Kerkvliet, J. (1994). Cheating by economics students: a comparison of survey results. Journal of Economic Education, 25(2), 121-133.

Kerkvliet, J., \& Sigmun, C. L. (1999). Can we control cheating in the classroom? Journal of Economic Education, 30(4), 331-351.

Magnus, J. R., Polterovich, V. M., Danilov, D. L., \& Savvateev, A. V. (2002). Tolerance of cheating: an analysis across countries. Journal of Economic Education, 33, 125-135.

McCabe, D. L., \& Trevino, L. K. (1997). Individual and contextual influences on academic dishonesty: a multicampus investigation. Research in Higher Education, 38(3), 379-396.

McCabe, D. L., Butterfield, K. D., \& Trevino, L. K. (2003). Faculty and academic integrity: the influence of current honor codes and past honor code experiences. Research in Higher Education, 44(3), 367-385.

Nowell, C., \& Laufer, D. (1997). Undergraduate student cheating in the fields of business and economics. Journal of Economic Education, 28, 3-12. 
Pulvers, K., \& Diekhoff, G. M. (1999). The relationship between academic dishonesty and college classroom environment. Research in Higher Education, 40(4), 487-498.

Rettinger, D. A., Jordan, A. E., \& Peschiera, F. (2004). Evaluating the motivation of other students to cheat: a vignette experiment. Research in Higher Education, 45(8), 873-890.

Rocha, M. F. \& Teixeira, A. C. (2005). Crime without punishment: an update review of the determinants of cheating among university students. FEP Working Papers $\mathrm{n}^{\circ} 191$, Faculdade de Economia, Universidade do Porto.

Sheard, J., \& Dick, M. (2003). Influences on cheating practice of graduate students in IT courses: what are the factors? ACM SIGCSE Bulletin, 35(3), 45-49.

Teixeira, A. C. C. (2005). Estimating human capital stock in Portugal. An update until 2001. Portuguese Journal of Social Science, 4(2), 101-120.

Tibbets, S. G. (1999). Differences between women and men regarding decisions to commit test cheating. Research in Higher Education, 40(3), 323-342.

Whitey, B. E., Jr. (1998). Factors associated with cheating among college students: a review. Research in Higher Education, 39(3), 235-274.

Wolpin, K. I. (1978). An economic analysis of crime and punishment in England and Wales, 1894-1967. Journal of Political Economy, 86(5), 815-40. 